\title{
Assessment of Significant Wave Height in the Taiwan Strait Measured by a Single HF Radar System
}

\author{
LINGHUI CAI ${ }^{\mathrm{a}}$ \\ College of Ocean and Earth Sciences, Xiamen University, Xiamen, China \\ Shaoping Shang, Guomei Wei, Zhigang He, Yanshuang Xie, And Ke LiU \\ College of Ocean and Earth Sciences, and Research and Development Center for Ocean Observation Technologies, \\ and Key Laboratory of Underwater Acoustic Communication and Marine Information Technology, \\ Ministry of Education, Xiamen University, Xiamen, China
}

TAO ZHOU

Nanjing Marine Radar Institute, Nanjing, China

JINQUAN CHEN AND FENG ZHANG

College of Ocean and Earth Sciences, Xiamen University, Xiamen, China

YAN LI

Environmental Science Research Center, Xiamen University, Xiamen, China

(Manuscript received 24 August 2018, in final form 7 May 2019)

\begin{abstract}
Dual high-frequency (HF) radar systems are often used to provide measurements of waves, winds, and currents. In this study, the accuracy of wave measurements using a single HF radar system (OS081H-A) was explored using datasets obtained during 5-27 January 2014 in the southwestern Taiwan Strait. We selected the study region as an area with $>90 \%$ coverage (i.e., the range was $<100 \mathrm{~km}$ ). Qualitative and quantitative intercomparison of wave measurements (by the radar and five buoys) and wave model products [from the Simulating Wave Nearshore (SWAN) model] were conducted. Intercomparison of the modeled and in situ significant wave height Hs showed that the model-predicted Hs could be considered to be acceptable for use as "sea truth" to evaluate the radarderived Hs, with mean bias from -0.45 to $-0.16 \mathrm{~m}$, mean absolute error (MAE) of $0.24-0.45 \mathrm{~m}$, and root-meansquare error of $0.31-0.54 \mathrm{~m}$. It was found that the MAE of radar-derived Hs was $\leq 1 \mathrm{~m}$ for $86 \%$ of the sector (except at the edge of sector) when the model-predicted Hs was $\geq 1.5 \mathrm{~m}$. In particular, the MAE was less than $0.6 \mathrm{~m}$ for $63 \%$ of the sector, which was mainly distributed in the area with a bearing from $-50^{\circ}$ to $+70^{\circ}$ and a range of $20-70 \mathrm{~km}$. The results are promising, but more work is needed. We employed a spatial distribution function for the MAE of the radar-derived Hs over the sample duration based on range, bearing, and mean radar-derived Hs.
\end{abstract}

\section{Introduction}

When electromagnetic waves are radiated by a vertically polarized antenna, the propagation loss of highfrequency $(\mathrm{HF})$ radio waves $(3-30 \mathrm{MHz})$ is small when

\footnotetext{
${ }^{\text {a }}$ Current affiliation: Xiamen Institute of Geological Engineering, Xiamen, China.
}

Corresponding authors: Shaoping Shang, spshang@xmu.edu.cn; Guomei Wei, weiguomei@163.com traveling over the sea surface. Based on the theory of Bragg scattering and the Doppler frequency effect, HF radars can be used to provide measurements of ocean waves, winds, and currents (Crombie 1955; Barrick 1971, 1977a; Barrick et al. 1977). Moreover, they are capable of all-weather remote sensing of large-area ocean surface dynamics with reasonably high precision.

Based on the theory formulated by Barrick (1972), ocean surface currents can be extracted based on the dispersion relation of gravity waves in deep water. In 
subsequent years, Barrick published several papers concerning quantitative interpretation on the mechanisms of first-order and second-order scattering when radar waves interact with the sea surface (Barrick 1972, 1977a,b; Barrick et al. 1974). The inversion technique for significant wave height $\mathrm{Hs}$ for the OS081H-A HF radar used in this study was based on Barrick's theory that relates $\mathrm{Hs}$ to the power ratio of the weighted total second-order spectra to the first-order peaks [the inversion technique is illustrated in Chu et al. (2015), and Barrick (1977a) and Heron and Heron (1998) contain more details].

The capability of measuring ocean currents using HF radar is considered satisfactory for the requirements of routine marine observations (Graber et al. 1997; Kohut et al. 2006; Liu et al. 2014). However, the inversion technique adopted for wind and wave measurements requires further improvement. Given the increasing number of deployments of HF radars for measuring waves in coastal oceans, the accuracy of the inversion technique has become of increasing concern and many validation studies have been undertaken in recent years to evaluate the performance of radars in estimating waves. Conventional validation studies of HF radar-derived waves are mainly based on comparison with fixed-point observations. This is because in situ devices have high precision and thus the evaluation results are generally reliable (Wyatt et al. 1999, 2006; Haus et al. 2010; Long et al. 2011; Lipa et al. 2014; Atan et al. 2016; Lorente et al. 2018). However, an obvious limitation of this approach is that the comparison results are limited to only a few points (mostly in the sector of highprecision coverage) and they do not reflect the full spatial distribution of the accuracy of HF radarderived waves. In addition, some studies have evaluated waves deduced by radar based on in situ data and model simulation results. For example, Wyatt et al. (2003) undertook two experiments to test and demonstrate the performance of a radar system on the coasts of Norway and Spain, and they reported the results of qualitative and quantitative intercomparison of wave measurements and wave model products at selected points. Hisaki (2014) analyzed the consistency of wave data obtained from HF radar, in situ observations, and model predictions in the East China Sea near Okinawa, Japan. In addition to conventional fixed-point intercomparison, he also compared the spatial distribution of the mean radar-estimated wave heights during the observation period with modelpredicted wave heights in a limited area, although he did not assess the spatial distribution of the errors of the radar-estimated wave heights.
In this study, our objective was to assess the accuracy of Hs deduced by a single HF radar system (OS081H-A) based not only on in situ observations but also on model-predicted Hs validated by the in situ data. We further analyzed the spatial distribution of the error of HF radar-derived Hs within the study area and a spatial distribution function was employed.

\section{Materials and methods}

\section{a. Significant wave height deduced by HF radar}

The OS081H-A HF radar was developed by the CSIC Pride (Nanjing) Intelligent Equipment System Co., Ltd. The HF radar used in this study was deployed on the coast of Dongshan County, Fujian Province, China (Fig. 1), and a set of wave data was collected in the southwestern Taiwan Strait during 5-27 January 2014. The radar worked at $7.8 \mathrm{MHz}$ with $30-\mathrm{kHz}$ bandwidth. A OS081H-A system is composed of two separate antenna arrays, an eight-element nonlinear receiving array and a three-element Yagi-Uda antenna for transmitting frequency-modulated interrupted continuous wave pulses. The spatial superresolution algorithm known as the minimum variance method (MVM; which is another type of beam-forming algorithm but with an adaptive weighting) is applied in the field of spatial spectrum estimation (Capon 1969; Wu et al. 2001). Based on the MVM algorithm, the Hs was measured by the single radar system with range and bearing resolutions of $5 \mathrm{~km}$ and $10^{\circ}$, respectively. However, for the convenience of users, the spatial resolution was set as $0.045^{\circ} \mathrm{N} \times 0.045^{\circ} \mathrm{E}$ for output. The wave data were archived every $10 \mathrm{~min}$ (collecting data over a period of $20 \mathrm{~min}$ ).

The research area was determined based on the spatial distribution of the percent of time for which spatial coverage was achieved over the sample duration (Fig. 1). The output of the cell was set to valid only if the signal-to-noise ratio of second-order sea echo fulfilled a predefined threshold $(5 \mathrm{~dB})$. Except for the removal of invalid data, which were set as -9999 by the software, the radar-derived Hs has not been further quality controlled. The percent coverage was calculated for each sample cell as the total number of estimates deemed valid divided by the total number of theoretical measurements. As the range (i.e., the distance between a sample cell and the radar site) increased, the coverage decreased. The boresight beam of the receiving array was centered at the azimuth angle of $132^{\circ}$ and the bearing of the sample cells ranged from $-70^{\circ}$ to $+70^{\circ}$ (negative angles were to the left of the boresight beam of the receiving array, and positive angles were to the right). 


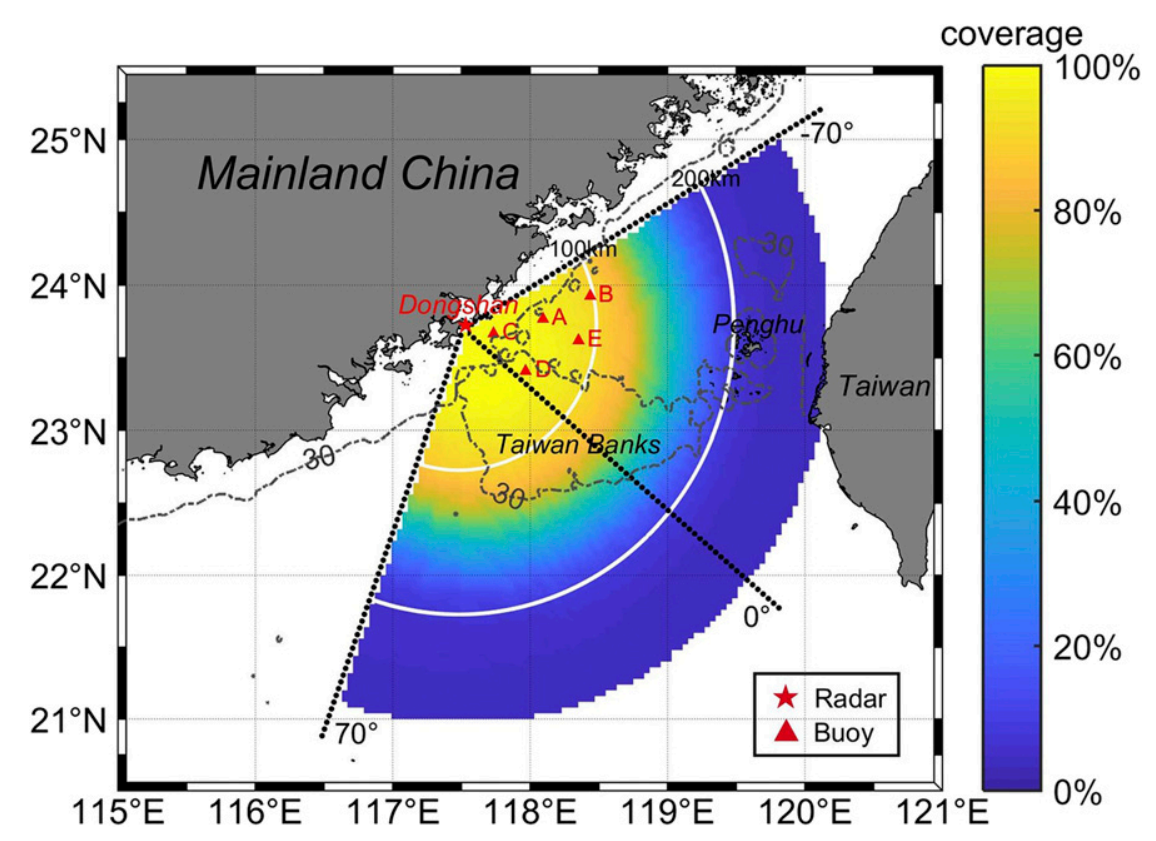

FIG. 1. Spatial coverage of Hs derived by the OS081H-A HF radar at 7.8 MHz during 5-27 Jans 2014. The star indicates the radar site, and the triangles indicate locations of the buoys. The water depths, with a grid resolution of $0.8 \mathrm{~min}$, were obtained online from the General Bathymetric Chart of the Oceans (http://www.gebco.net).

For sample cells at the same range, the coverage of cells nearest the boresight beam of the receiving array was slightly higher than cells at the edge of the sector. This means the coverage decreased as the bearing increased. A reduction in the number of data returned with increasing distance from the radar site was expected. Within the range of $100 \mathrm{~km}$, the percent coverage exceeded $90 \%$. In this area, the radar had the capability of continuous observation, although the coverage decreased markedly when the range increased beyond $100 \mathrm{~km}$. Therefore, we considered the region with percent coverage $>90 \%$ (i.e., range of $<100 \mathrm{~km}$ ) as the study area within which to explore the accuracy of wave measurements using the radar system.

The Taiwan Banks (TB) is located in the south of our study area, which is a shoal in the southern entrance of the Taiwan Strait between the South and East China Seas. The TB extends from the west near Dongshan County to the east of the Penghu Islands (Fig. 1). The water depth in the TB is relatively shallow, from 10 to $35 \mathrm{~m}$, with an average depth of $20 \mathrm{~m}$. The western TB has deeper water depths, with an average depth of $35 \mathrm{~m}$, while the eastern TB has relatively shallower water depths $(<15 \mathrm{~m})$. The largest submarine sand waves in the world are found in the TB. The height of sand waves can reach a maximum of $20 \mathrm{~m}$ (Shao et al. 2011; Zhang et al. 2014).

\section{b. Significant wave height observed by buoys}

Five 3-m Discus buoys were deployed in the study region on 5 January 2014, with mooring location distances ranging from 20 to near $100 \mathrm{~km}$ from the radar site (see Fig. 1 and Table 1). Wave and wind sensors were integrated in the Discus buoys. In this way, the data could be received in real time and data quality was satisfied. In situ measurements at stations A, C, and E lasted for more than 20 days continuously, whereas the observations at stations B and D were interrupted on January 14.

To ensure reliability of the evaluation results of HF radar-derived Hs, the wave data obtained by the five buoys were quality controlled. First, quality control (QC) was performed for the buoy wind data. The wind direction in the Taiwan Strait is generally stable from the northeast during the winter monsoon, and it is also modified by the channel effect of the Taiwan Strait; good correlations were found between the wind data of the five buoys (Guo et al. 2010). A complex correlation analysis was conducted for the wind vectors at different locations during the experiment [see Kundu (1976) for more details about the complex correlation coefficient (CCC)]. The results showed that the CCCs between the two different stations were all greater than 0.91 (Table 2), indicating the wind vectors were qualified for QC of 
TABLE 1. Information on the in situ wave measurements.

\begin{tabular}{|c|c|c|c|c|c|c|c|}
\hline Stations & Lon $\left({ }^{\circ} \mathrm{E}\right)$ & Lat $\left({ }^{\circ} \mathrm{N}\right)$ & Water depth (m) & Range (km) & Bearing $\left(^{\circ}\right)$ & Obs time & $\begin{array}{c}\text { Valid data after } \\
\text { QC }(\%)\end{array}$ \\
\hline A & 118.0333 & 23.7833 & 38 & 57.5 & -55 & 5-27 Jan 2014 & 96.3 \\
\hline B & 118.3833 & 23.9500 & 46 & 97 & -60 & 5-14 Jan 2014 & 95.0 \\
\hline $\mathrm{C}$ & 117.6833 & 23.6833 & 27 & 20.5 & -50 & 5-27 Jan 2014 & 94.8 \\
\hline $\mathrm{D}$ & 117.9167 & 23.4167 & 29 & 51 & -13 & 5-14 Jan 2014 & 97.2 \\
\hline $\mathrm{E}$ & 118.1950 & 23.6347 & 41 & 72.5 & -40 & 5-27 Jan 2014 & 96.8 \\
\hline
\end{tabular}

the wave data. Then QC for the wave data was undertaken based on the quality-controlled wind data. For a single point in the Taiwan Strait, good correlation was found between the wave and wind data (Lin and Liao 1983). Hence, QC for the wave data was performed by analyzing the consistency of the temporal variation between the wave and wind vectors (here, we took the significant wave height and predominant wave direction as the "wave vector"). The time series of wave vector exhibits reasonable consistency with wind vector at stations A, B, C, and $\mathrm{D}$ with reasonably high correlation $(\mathrm{CCC}>0.92)$ (Table 3$)$. The lower correlation $(\mathrm{CCC}=0.4)$ at station $\mathrm{E}$ was because the predominant wave direction was not of acceptable quality. Fortunately, the correlation analysis between $\mathrm{Hs}$ and wind speed showed that the Hs at station $\mathrm{E}$ was deemed adequate for use (with the correlation coefficient was 0.82). The QC results showed that over $95 \%$ of data were valid during the period of continuous observation (Table 1), indicating the continuity and quality of the in situ wave height data at the five locations were satisfactory, so that they could be used to assess the accuracy of HF radar-derived Hs.

\section{c. Significant wave height simulated by numerical model}

Recently, many studies have used the third-generation Simulating Wave Nearshore (SWAN) model to simulate ocean waves in coastal regions (Booij et al. 1999; Ris et al. 1999; Rogers et al. 2003). Previous research has proven that the SWAN model has acceptable performance in wave simulation in the Taiwan Strait (Feng et al. 2013; Ji et al. 2013). Therefore, we attempted to use the simulation

TABLE 2. Correlation analysis (CCC values) of the in situ wind vectors at different stations.

\begin{tabular}{lccccc}
\hline \hline & A & B & C & D & E \\
\hline A & 1 & 0.942 & 0.975 & 0.981 & 0.971 \\
B & - & 1 & 0.915 & 0.936 & 0.914 \\
C & - & - & 1 & 0.950 & 0.948 \\
D & - & - & - & 1 & 0.964 \\
E & - & - & - & - & 1 \\
\hline
\end{tabular}

results of the SWAN model (version 40.85) to verify the spatial distribution of HF radar-derived Hs in our study.

For wave simulation in coastal regions, the computational grid, driving field (wind data), and bathymetric data play important roles in the SWAN model. When compared with other products of sea surface wind (e.g., those provided by National Centers for Environmental Prediction and ERA-Interim data provided by the European Centre for Medium-Range Weather Forecasts), the Cross-Calibrated Multi-Platform (CCMP) wind product has better performance in the Taiwan Strait (Kuang et al. 2015). Therefore, it was selected for use as the driving field for the SWAN model. The CCMP is provided free of charge by NASA's Physical Oceanography Distributed Active Archive Center (PO.DAAC; it can be downloaded at http:// rda.ucar.edu/datasets/ds744.9/). In our simulation, the spatial range of the CCMP was $17.825^{\circ}-29.825^{\circ} \mathrm{N}$, $109.875^{\circ}-129.875^{\circ} \mathrm{E}$ with spatial resolution of $0.25^{\circ}$, a time span covering 5-27 January 2014, and temporal resolution of $6 \mathrm{~h}$. Rectangular grids with spatial resolution of $1 / 40^{\circ} \mathrm{N} \times 1 / 40^{\circ} \mathrm{E}$ was applied in the computation. To improve the accuracy of the simulation results in the complex coastal regions, the bathymetric data used for the nearshore area of Fujian Province comprised gridded bathymetry databased on in situ measurements, while the data for other areas were obtained from etop01 provided by NOAA (https:// www.ngdc.noaa.gov/mgg/global/global.html). The time step of the model computation was $1800 \mathrm{~s}$.

\section{d. Statistical metrics}

We evaluated the performance of Hs derived by the OS081H-A HF radar in the study area by following

TABLE 3. Correlation analysis between the in situ wind and wave data at stations A-E. The complex correlation coefficients were calculated between the wave vector and wind vector. The correlation coefficients were calculated between the significant wave height and wind speed.

\begin{tabular}{lccccc}
\hline \hline Stations & A & B & C & D & E \\
\hline CCC & 0.957 & 0.922 & 0.950 & 0.966 & 0.401 \\
CC & 0.894 & 0.911 & 0.877 & 0.893 & 0.823 \\
\hline
\end{tabular}



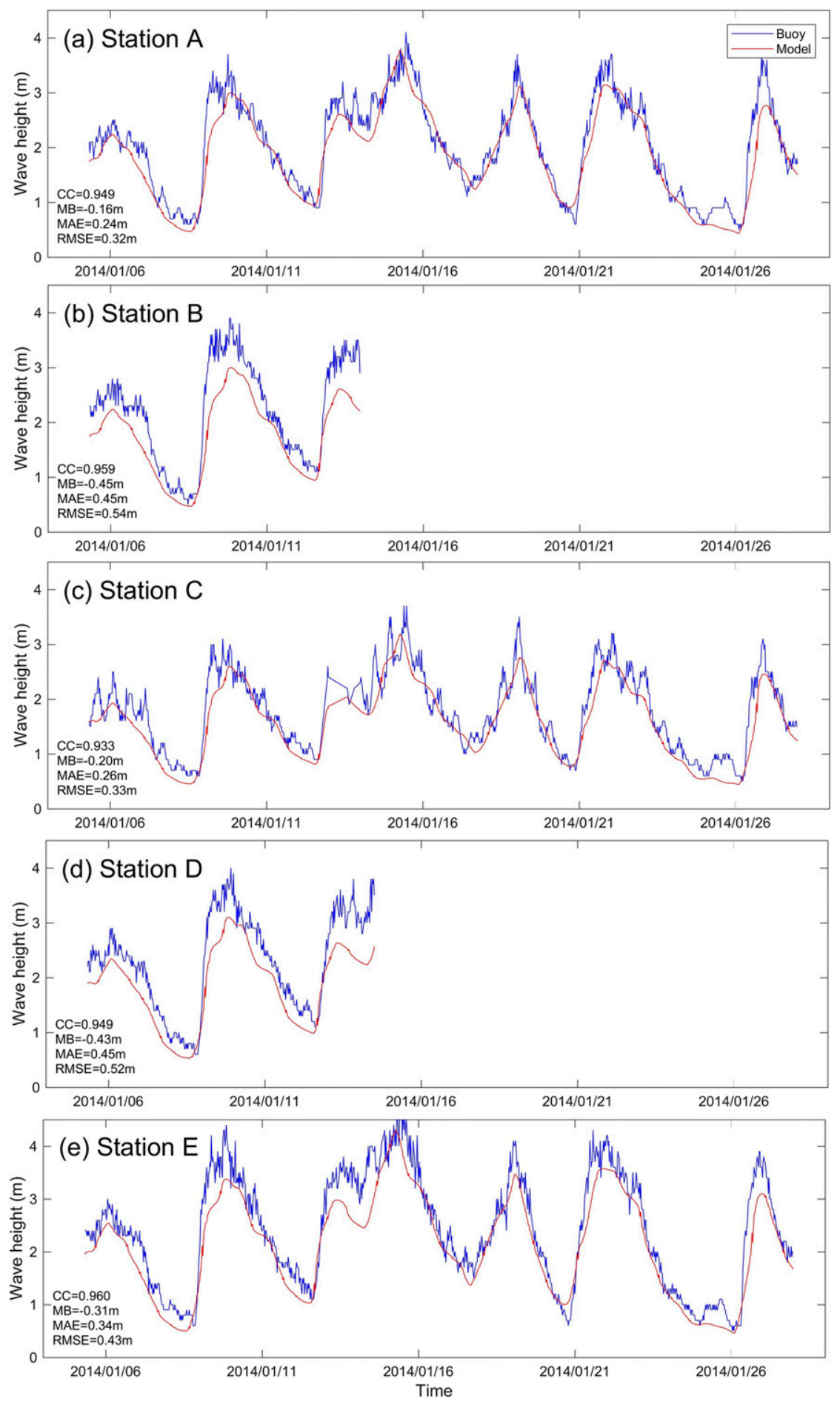

FIG. 2. Comparisons of Hs between model and buoys.

three steps. Step 1 assessed the reliability of modelpredicted Hs based on in situ Hs observed by the five buoys. Step 2 evaluated the radar-derived Hs based on in situ Hs at the locations of the buoys and obtained the accuracy of radar-derived Hs at different points.
Step 3 explored the spatial distribution of the accuracy of the HF radar-derived $\mathrm{Hs}$ based on validated model-predicted Hs.

A widely used statistical measure of the level of agreement between two scalar time series is the correlation 
TABLE 4. Comparison statistics of Hs among the model, radar and buoys. Here, Hi, Hm, and Hr represent the mean in situ Hs, mean model-predicted Hs, and mean radar-derived Hs over the sample duration, respectively.

\begin{tabular}{|c|c|c|c|c|c|c|c|c|c|c|c|c|}
\hline \multirow[b]{2}{*}{ Station } & \multicolumn{4}{|c|}{ Model vs buoy } & \multicolumn{4}{|c|}{ HF radar vs buoy } & \multicolumn{3}{|c|}{ Mean Hs } & \multirow[b]{2}{*}{$N$} \\
\hline & $\mathrm{MB}(\mathrm{m})$ & $\operatorname{MAE}(\mathrm{m})$ & RMSE (m) & $\mathrm{CC}$ & $\mathrm{MB}(\mathrm{m})$ & MAE (m) & $\operatorname{RMSE}(\mathrm{m})$ & $\mathrm{CC}$ & $\mathrm{Hi}(\mathrm{m})$ & $\operatorname{Hm}(\mathrm{m})$ & $\mathrm{Hr}(\mathrm{m})$ & \\
\hline A & -0.16 & 0.24 & 0.31 & 0.949 & 0.78 & 0.80 & 0.89 & 0.883 & 2.03 & 1.87 & 2.81 & 1047 \\
\hline B & -0.45 & 0.45 & 0.54 & 0.960 & 1.00 & 1.10 & 1.48 & 0.402 & 2.19 & 1.74 & 3.19 & 393 \\
\hline $\mathrm{C}$ & -0.20 & 0.26 & 0.33 & 0.933 & 0.53 & 0.55 & 0.61 & 0.912 & 1.77 & 1.57 & 2.30 & 1032 \\
\hline $\mathrm{D}$ & -0.43 & 0.44 & 0.52 & 0.959 & -0.11 & 0.48 & 0.57 & 0.823 & 2.27 & 1.83 & 2.15 & 427 \\
\hline $\mathrm{E}$ & -0.31 & 0.34 & 0.43 & 0.960 & 0.32 & 0.52 & 0.77 & 0.749 & 2.43 & 2.13 & 2.75 & 1054 \\
\hline
\end{tabular}

coefficient (CC) or the coefficient of determination $\left(\mathrm{CC}^{2}\right)$. The mean bias (MB), mean absolute error (MAE), and root-mean-square error (RMSE) are also measures used commonly to evaluate the degree of consistency between the two different datasets:

$$
\begin{aligned}
\mathrm{MB} & =\frac{1}{N} \sum_{i=1}^{N}\left(y_{i}-x_{i}\right), \\
\mathrm{MAE} & =\frac{1}{N} \sum_{i=1}^{N}\left|y_{i}-x_{i}\right|, \quad \text { and } \\
\mathrm{RMSE} & =\left[\frac{1}{N} \sum_{i=1}^{N}\left(y_{i}-x_{i}\right)^{2}\right]^{1 / 2} .
\end{aligned}
$$

Here, $x_{i}$ and $y_{i}$ represented the Hs of two different datasets. In step $1, y_{i}$ represented the model-predicted Hs and $x_{i}$ represented the in situ Hs. In step 2, $y_{i}$ represented the radar-derived $\mathrm{Hs}$ and $x_{i}$ represented the in situ Hs. In step 3, $y_{i}$ represented the radar-derived $\mathrm{Hs}$ and $x_{i}$ represented the modelpredicted Hs. Parameter $N$ is the total number of matched-up observations.

\section{Comparison results of significant wave height}

\section{a. Model versus buoys}

We assessed the accuracy of the model-predicted Hs based on in situ Hs observed simultaneously by five buoys located at stations A-E. Half-hourly time series of Hs at these locations are shown in Fig. 2 for the sampled durations when both simulation and in situ data were available and deemed valid. Albeit with slight underestimation (MB from -0.45 to $-0.16 \mathrm{~m}$ ), the model-predicted $\mathrm{Hs}$ matches the in situ Hs surprisingly well with $\mathrm{CC}>0.93$. Comparison statistics provided in Table 4 show that for all five pairs of $\mathrm{Hs}$ [mean in situ $\mathrm{Hs}(\mathrm{Hi})$ in a range of 1.77-2.43 m], the MAE is within the range $0.24-0.45 \mathrm{~m}$, and the RMSE is within the range $0.31-0.54 \mathrm{~m}$. Consequently, the simulated Hs could be considered to be acceptable for use in assessing the accuracy of HF radar-derived Hs in the Taiwan Strait.

\section{b. HF radar versus buoys}

Comparison of HF radar-derived $\mathrm{Hs}$ and concurrently measured in situ Hs were shown in Fig. 3. The time series of Hs observed by the radar exhibits reasonable consistency with that of the buoys at stations A, C, D, and E with reasonably high correlation (CC > 0.75) (Table 4). However, the radar-derived Hs was generally overestimated at stations $\mathrm{A}$ and $\mathrm{C}$, with $\mathrm{MB}$ of 0.78 and $0.55 \mathrm{~m}$, respectively. The amplitude of radar-derived $\mathrm{Hs}$ was smaller than in situ $\mathrm{Hs}$ at station D. The radar-derived Hs was apparently higher than the in situ $\mathrm{Hs}$ at station $\mathrm{B}$, with the comparatively bigger difference $(\mathrm{MB}=1.0 \mathrm{~m}, \mathrm{MAE}=1.1 \mathrm{~m}$, and RMSE $=1.48 \mathrm{~m})$ and lower correlation $(\mathrm{CC}=0.4)$. The uncertainty was probably introduced by the large range (close to $100 \mathrm{~km}$ ) and the large bearing $\left(-60^{\circ}\right)$. For in situ Hs of $\geq 1.5 \mathrm{~m}$ (except station D that shows slight underestimation), the radar-derived $\mathrm{Hs}$ at other stations was generally overestimated. Nevertheless, for in situ $\mathrm{Hs}$ of $<1.5 \mathrm{~m}$ (i.e., the data below the black dotted line in Fig. 3), the radar-derived Hs was obviously overestimated at all locations.

The comparison statistics of $\mathrm{Hs}$ between the radar and the buoys (Table 4) revealed that as the range or the bearing increased, the error of the radar-derived $\mathrm{Hs}$ became larger. Except at station B, the MAE is within the range $0.48-0.80 \mathrm{~m}$ and the RMSE is within the range $0.57-0.89 \mathrm{~m}$. The limitation of the comparison with in situ data is that the comparison results are limited to only a few points, and it is impossible to evaluate the spatial distribution of the accuracy of the radar wave field. Therefore, the radar-derived $\mathrm{Hs}$ in the study area was evaluated further based on the validated modelpredicted Hs.

\section{c. HF radar versus model}

Taking the model-predicted Hs as "sea truth," the spatial distributions of CC, MB, MAE, and RMSE for the $\mathrm{HF}$ radar-derived Hs over the sample duration were 

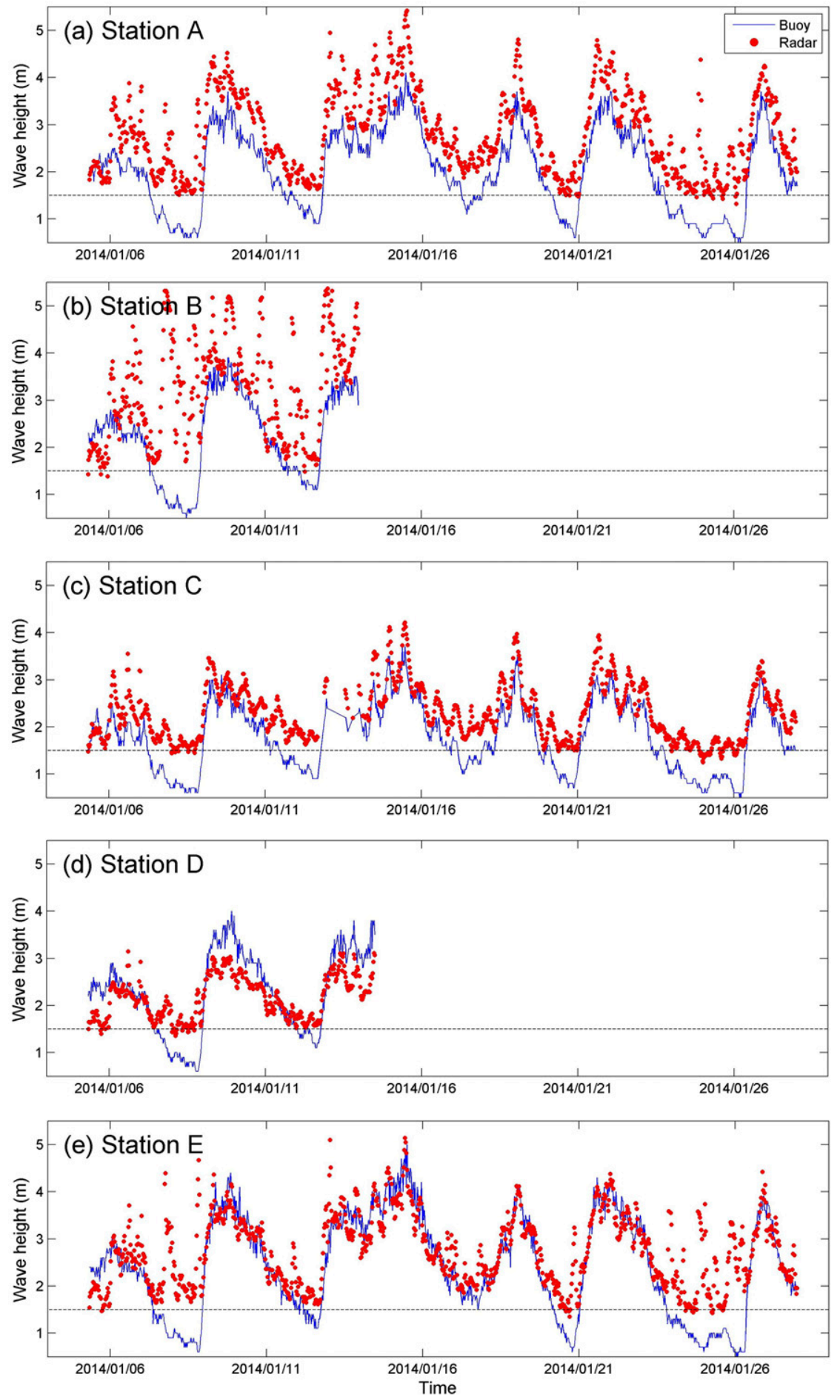

FIG. 3. Comparisons of Hs between OS081H-A HF radar and buoys.

shown in Fig. 4. The CC between the radar-derived Hs and model-predicted $\mathrm{Hs}$ revealed that as the range increased, the CC became smaller. The CC on the left side of the boresight beam was generally larger than on the right side at the same bearing. The lower correlation found in the south of our study area was probably effected by the sand waves in the TB.

The spatial distributions of errors were different from that of CC. The error of the radar-derived Hs was smallest near the boresight beam of the receiving array 

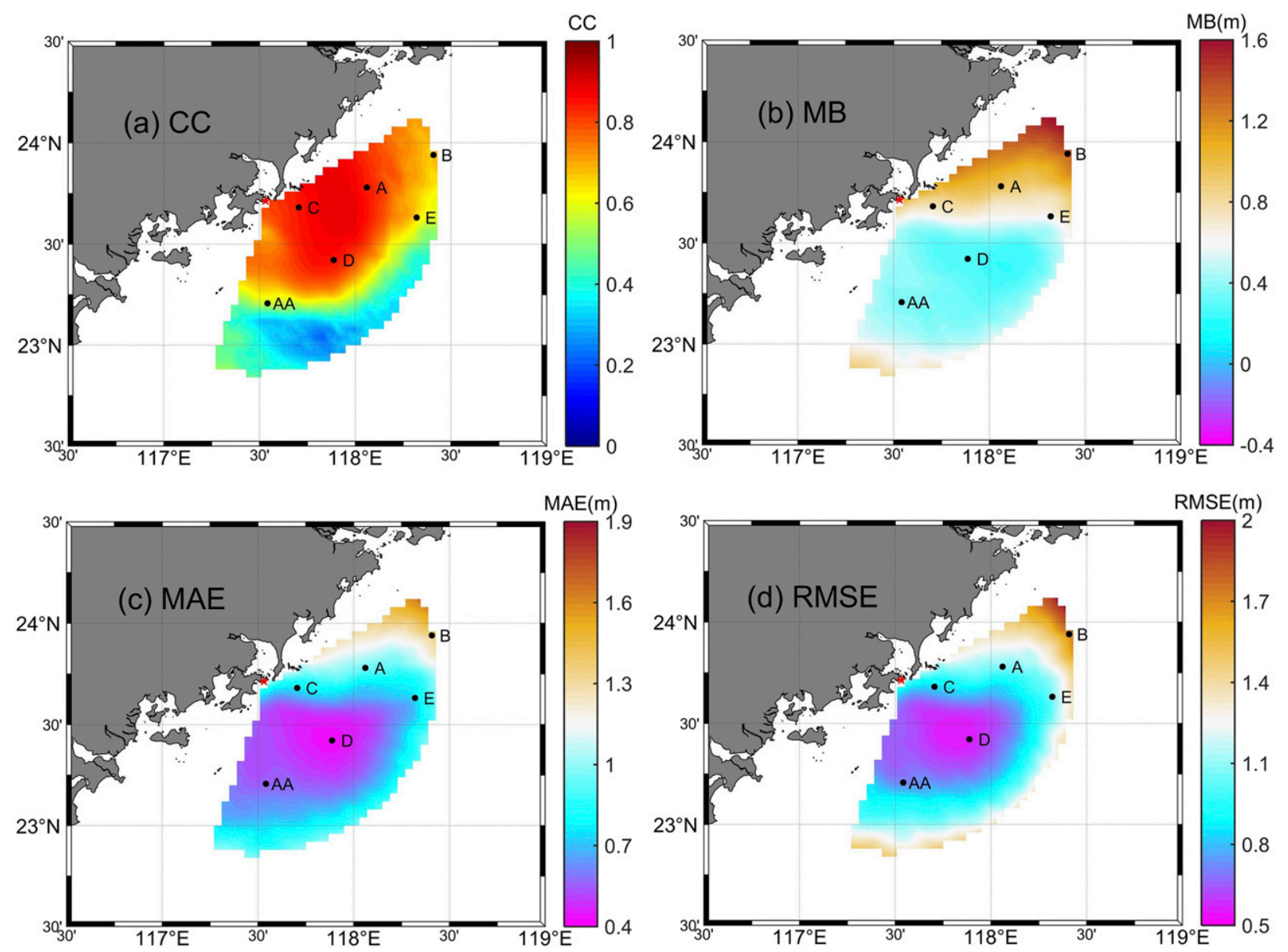

FIG. 4. Spatial distribution of (a) correlation coefficient, (b) mean bias, (c) mean absolute error, and (d) root-mean-square error for radar-derived Hs based on model-predicted Hs. Stations A-E indicate the locations of the buoys. Without in situ observations, station AA, located to the right of the radar beam, had the same bearing (station A was $-55^{\circ}$; station AA was $55^{\circ}$ ) and the same range as station A.

and it increased as the bearing increased. The error on the right side of the boresight beam was generally smaller than on the left side at the same bearing. Except for the nearshore area (within a few kilometers offshore), the error of the radar-derived Hs also increased as the range increased.

In comparison with the model-predicted Hs, the radar-derived $\mathrm{Hs}$ was generally overestimated in the study area $(\mathrm{MB}=0.2-1.7 \mathrm{~m}$, with $\mathrm{MB}<0.9 \mathrm{~m}$ for $80 \%$ of the sector), especially at the upper edge of the sector. The MAE was also significantly larger at the upper edge of the sector, while it was $\leq 1 \mathrm{~m}$ in all other areas (i.e., $83 \%$ of the area within the sector), and the MAE in the high-precision area was less than $0.6 \mathrm{~m}$ (i.e., $34 \%$ of the area within the sector). The spatial distribution of the RMSE for the radar-derived Hs was similar to that of the MB and MAE. Except for larger values at the upper and lower edges of the sector, the RMSE was $0.5-1.2 \mathrm{~m}$.

\section{Discussion}

\section{a. Evaluation of radar-derived significant wave heights at different sea states}

Comparison of the time series of Hs obtained from the radar and the buoys (analyzed in section $3 b$ ) showed that when in situ Hs was $<1.5 \mathrm{~m}$, the radar-derived Hs was obviously overestimated. Hence, we evaluated the accuracy of the radar-derived $\mathrm{Hs}$ at different sea states by calculating the error of the radar-derived Hs with reference to the model-predicted $\mathrm{Hs}$ of $\geq 1.5$ and $<1.5 \mathrm{~m}$ (Fig. 5). As shown in Fig. 4, the spatial distribution of the RMSE for the radar-derived Hs was similar to that of the MB and MAE. Hence, only the MB and MAE were analyzed in this section.

The features of spatial distribution patterns of the $\mathrm{MB}$ and MAE for the model-predicted $\mathrm{Hs}$ of $\geq 1.5 \mathrm{~m}$ (Figs. 5a,b) were found similar to those in Fig. 4. However, the radar-derived Hs was slightly underestimated 

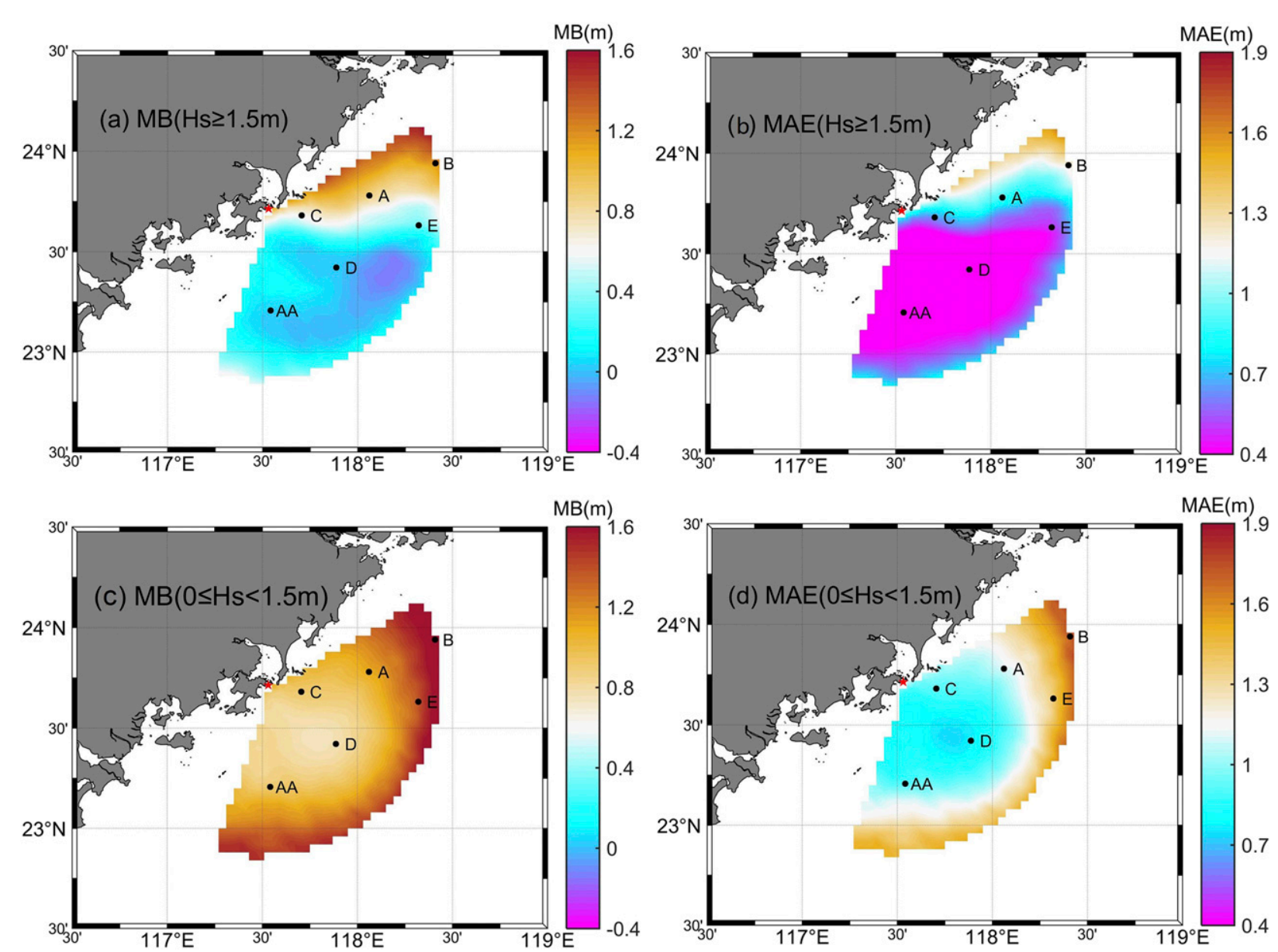

FIG. 5. Spatial distributions of MB and MAE for radar-derived Hs at different sea states: (a),(c) MB and (b),(d) MAE of radar-derived Hs when model-predicted Hs was (top) $\geq 1.5$ and (bottom) $<1.5 \mathrm{~m}$.

in the south of the sector. The magnitude of the MAE decreased significantly after the removal of modelpredicted $\mathrm{Hs}$ of $<1.5 \mathrm{~m}$. The MAE was $\leq 1 \mathrm{~m}$ for $86 \%$ of the area within the sector, and was $\leq 0.6 \mathrm{~m}$ for $63 \%$ of the sector (mainly distributed in the area with a bearing from $-50^{\circ}$ to $+70^{\circ}$ and a range of $20-70 \mathrm{~km}$ ). The MAE in the high-precision area was $<0.4 \mathrm{~m}(36 \%$ of the area within the sector). For model-predicted $\mathrm{Hs}$ of $<1.5 \mathrm{~m}$ (i.e., lower sea state), the error of the radar-derived $\mathrm{Hs}$ increased significantly (Figs. 5c,d). The MB and MAE in the high-precision area was less than $1 \mathrm{~m}(37 \%$ of the area within the sector) and it was greater than $1.0 \mathrm{~m}$ in all other areas.

The Hs deduced by the OS081H-A HF radar showed reasonable correlation with that simulated by the SWAN model; however, the comparison results also indicated overestimation by the radar in low sea states. This can be explained by the relatively greater effects of noise and interference in the case of low sea states where second-order sea echoes are weak in comparison with higher sea states. In this study, the OS081H-A HF radar was operated at $7.8 \mathrm{MHz}$, while the wavelength of a resonant sea wave was about $20 \mathrm{~m}$; thus, such waves failed to obtain sufficient energy to develop, meaning the echoes were weak and of poor stability, which led to the poor results (Barrick 1972; Wu et al. 2009). Based on the inversion theory of radar-derived Hs, the value of $h$ generally meets the condition $0.1 \leq k h \leq 1(\mathrm{Hs} \approx 2 h)$, where $k$ is the radar wavenumber and $h$ is RMS wave height (Barrick 1977a; Wyatt 2002). With work frequency of $7.8 \mathrm{MHz}$, the OS081H-A HF radar is adequate for measuring $\mathrm{Hs}$ within the range $1.22-12.2 \mathrm{~m}$.

In summary, the results preliminarily demonstrated that a single OS081H-A HF radar could provide useful information in $\mathrm{Hs}$ measurement with some limitations when the actual $\mathrm{Hs}$ was $\geq 1.5 \mathrm{~m}$. Conversely, when the actual $\mathrm{Hs}$ was $<1.5 \mathrm{~m}$, the accuracy of radar-derived Hs was poor and needed improvement. 

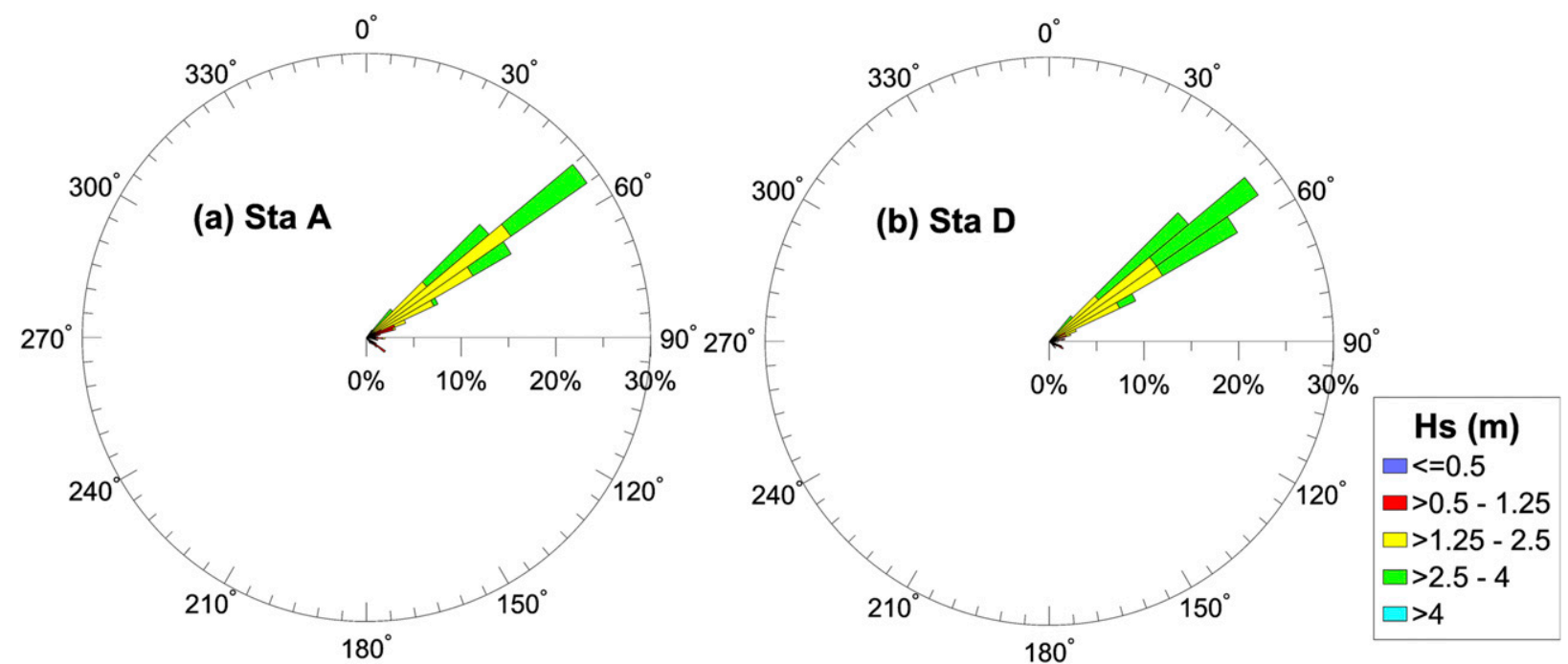

FIG. 6. Rose plots of predominant wave direction at stations (a) A and (b) D. The color scale indicates the Hs values. The radius axis scale designates the frequency of occurrence of the waves.

\section{b. Spatial distribution of error of radar-derived significant wave height}

\section{1) INFLUENCING FACTORS OF ACCURACY OF RADAR-DERIVED SIGNIFICANT WAVE HEIGHT}

\section{(i) Dominant wave direction}

Barrick (1977a) derived a wave height correction factor for three different radar/wave directions: $|\Phi|=$ $0^{\circ} / 180^{\circ}, 45^{\circ} / 135^{\circ}$, and $90^{\circ}$ (where $\Phi$ is the angle between the radar bearing and the dominant wave direction), and found that the accuracy of the inversion technique for HF radar-derived wave height is highly dependent on $\Phi$. With reference to the three directions in Barrick's theoretical predictions, we used three locations in our research (i.e., stations A, D, and AA; Fig. 4). Without in situ observations, station AA located to the right of the radar beam had the same bearing (station $\mathrm{A}:-55^{\circ}$; station $\mathrm{AA}:+55^{\circ}$ ) and the same range as station $\mathrm{A}$.

We considered the wave roses of stations A and D during 5-14 January 2014 (Fig. 6) and found that the predominant wave directions were mostly distributed in the range $45^{\circ}-60^{\circ}$ for the two stations $(64 \%$ and $70 \%$ of the data for station $\mathrm{A}$ and station $\mathrm{D}$, respectively). For $\mathrm{Hs} \geq 1.5 \mathrm{~m}, 86 \%$ of the predominant wave directions were distributed in the range $45^{\circ}-60^{\circ}$. We inferred that the distribution of the predominant wave direction for station AA was similar to stations $\mathrm{A}$ and $\mathrm{D}$ because the stations were all in the same wind fetch and all were affected by the channel effect of the Taiwan Strait. From the predominant wave directions and the locations of the three stations, we calculated that $\Phi$ was $17^{\circ}-32^{\circ}, 59^{\circ}-74^{\circ}$, and $38^{\circ}-53^{\circ}$ for station A, D, and AA, respectively. We noted that the value of $k \times$ Hs was in the range $0.1-0.65$ (i.e., $k h$ was $0.05-0.33$; for $\mathrm{Hs} \geq 1.5 \mathrm{~m}, k h$ was $0.12-0.33$ ), where Hs was significant wave height measured by the buoys. Based on the theoretical results of Barrick (1977a), we inferred that the accuracy of radar-derived Hs at station AA was better than at station $\mathrm{A}$; station $\mathrm{D}$ had the best accuracy. This result was identical to the results described in sections $3 \mathrm{~b}$ and 3c. Obviously, $\Phi$ is another factor that can affect the spatial distribution of the error of Hs deduced by radar. The accuracy quoted above can explain the accuracy found at stations with the same bearing (to the left or right of the radar beam) and the same range but with different uncertainty, which is dependent on $\Phi$.

\section{(ii) Sand waves on the Taiwan Banks}

The comparatively lower correlation found in the south of the study area (Fig. 4a) was probably influenced by the shallow waters and the sand waves on the TB. For one thing, based on the wavecurrent interaction theory, above sand waves on the seafloor, sea surface short waves are modulated by the submarine topography (Shao et al. 2011). For another, according to the theoretical analysis and the field experimental results in the sand wave-like bed (Bailard et al. 1992; Zhang et al. 2012), band gap and wave localization are suggested as the physical mechanism of sea surface waves propagating through natural large-scale sand waves in the TB. Greater wave steepness was found in the TB, 

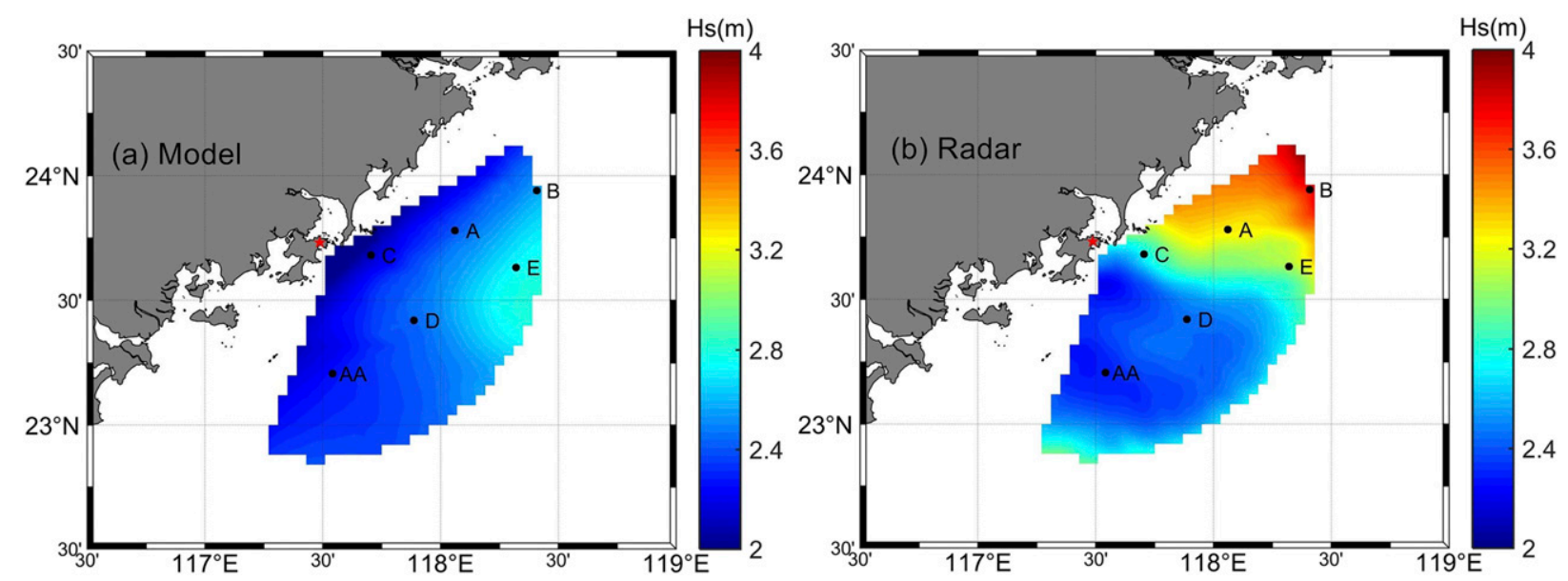

FIG. 7. Mean values of (a) model-predicted and (b) radar-derived Hs over the sample duration.

which could lead to the augmentation of radar sea echo.

As we mentioned above (section 2c), the bathymetric data play an important role in wave simulation by the SWAN model. However, etop01 (and the other bathymetry models) falls to determine bathymetry in the TB with sand waves overlaying. Hence, because of the effect of shallow waters and the sand waves on the TB, the accuracy of modelpredicted Hs was lower.

\section{(iii) Mean radar-derived $\mathrm{Hs}$}

To obtain the mean $\mathrm{Hs}$ for the model $(\mathrm{Hm})$ and radar (Hr), all of the Hs data collected over the sample duration were averaged for each sample cell in the study area (Fig. 7). The Hm increased with increasing distance from the coastline. The spatial distribution of $\mathrm{Hr}$ was similar to that of $\mathrm{Hm}$ on the right side of the boresight beam. However, the $\mathrm{Hr}$ was significantly larger than the $\mathrm{Hm}$ in the north of the sector. The spatial variability of $\mathrm{Hr}$ was larger than that of $\mathrm{Hm}$. The difference of spatial distribution between $\mathrm{Hr}$ and $\mathrm{Hm}$ was probably introduced by the effect of $\Phi$ on the radar-derived Hs and the underestimation of model-predicted Hs (analyzed in section 3a).

The $\mathrm{Hr}$ increased from south to north and the values were all greater than $3 \mathrm{~m}$ at the upper edge of the sector. The features of the spatial distribution pattern were similar with those of the error of the radar-derived Hs. Clear correlation was visually evident in the scatterplot shown in Fig. 8a; that is, the MAE of the radar-derived $\mathrm{Hs}$ increased as the $\mathrm{Hr}$ increased.

\section{(iv) Range and bearing}

The features of spatial distribution patterns of the MAE and RMSE for the radar-derived Hs showed the accuracy of wave measurements by radar was influenced by both the range $S$ and the bearing $\theta$, and the correlation between them was analyzed further from the scatterplots shown in Figs. 8b and 8c. Comparison of the MAE and the range (Fig. 8b) showed that the optimal radar performance was in the area with a range of $20-65 \mathrm{~km}$, in which the MAE of most sample cells was less than $0.6 \mathrm{~m}$. As anticipated, the MAE increased significantly with increasing distance for ranges beyond $65 \mathrm{~km}$. The variability of the MAE with bearing (Fig. 8c) showed that the MAE of sample cells close to the boresight beam of the receiving array was small (i.e., most MAEs were approximately $0.5 \mathrm{~m}$ ) and that the MAE increased with increasing bearing. It was apparent for sample cells with the same bearing that the MAE to the left of the radar beam was significantly larger than that to the right and that the MAE to the left of the radar beam increased rapidly as the bearing increased. We offered an explanation of this phenomenon in the first part of this section.

\section{2) SPATIAL DISTRIBUTION FUNCTION OF ERROR}

As analyzed above, if it is wished to obtain better accuracy for radar-derived $\mathrm{Hs}$, alternative techniques for the estimation of $\Phi$ should be adopted; however, it is not possible to deduce precisely the dominant wave direction by the OS081H-A HF radar. Hence, for many applications, it might be convenient to ignore the dependence on $\Phi$. To elucidate further the correlation between the MAE of Hs deduced by radar and the influencing factors mentioned above, we employed a spatial distribution function of the error. A ternary quadratic equation was fitted in our research to establish the relationship between the MAE and the three variables, expressed as follows: 

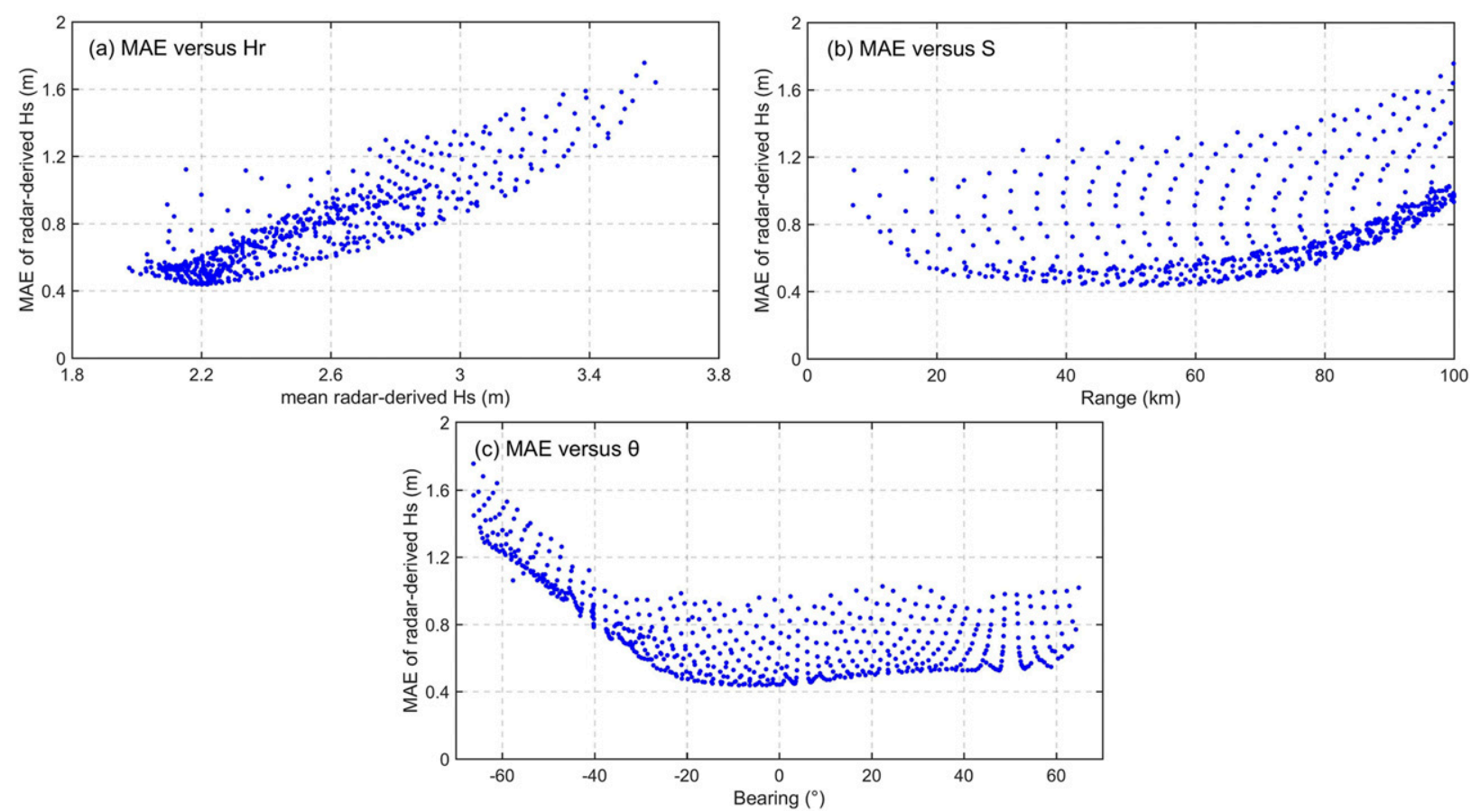

FIG. 8. Scatterplots of the MAE of radar-derived Hs vs (a) the mean radar-derived Hs, (b) the range, and (c) the bearing.

$$
\begin{aligned}
\operatorname{MAE}(S, \theta, \mathrm{Hr})= & -0.002 S+0.011 \theta+2.3 \times 10^{-4} S^{2} \\
& +8.5 \times 10^{-5} S \theta-0.010 S \mathrm{Hr} \\
& +4.2 \times 10^{-5} \theta^{2}-0.0066 \theta \mathrm{Hr} \\
& +0.22 \mathrm{Hr}^{2}
\end{aligned}
$$

where the unit of MAE is meters, the range of $\theta$ is $\left[-70^{\circ},+70^{\circ}\right]$, the range of $S$ is $[5,100 \mathrm{~km}]$, and the range of $\mathrm{Hr}$ is $[0,6 \mathrm{~m}]$.

The spatial distribution of the MAE calculated by Eq. (4) is shown in Fig. 9. The main feature of the pattern of the spatial distribution is similar to that in

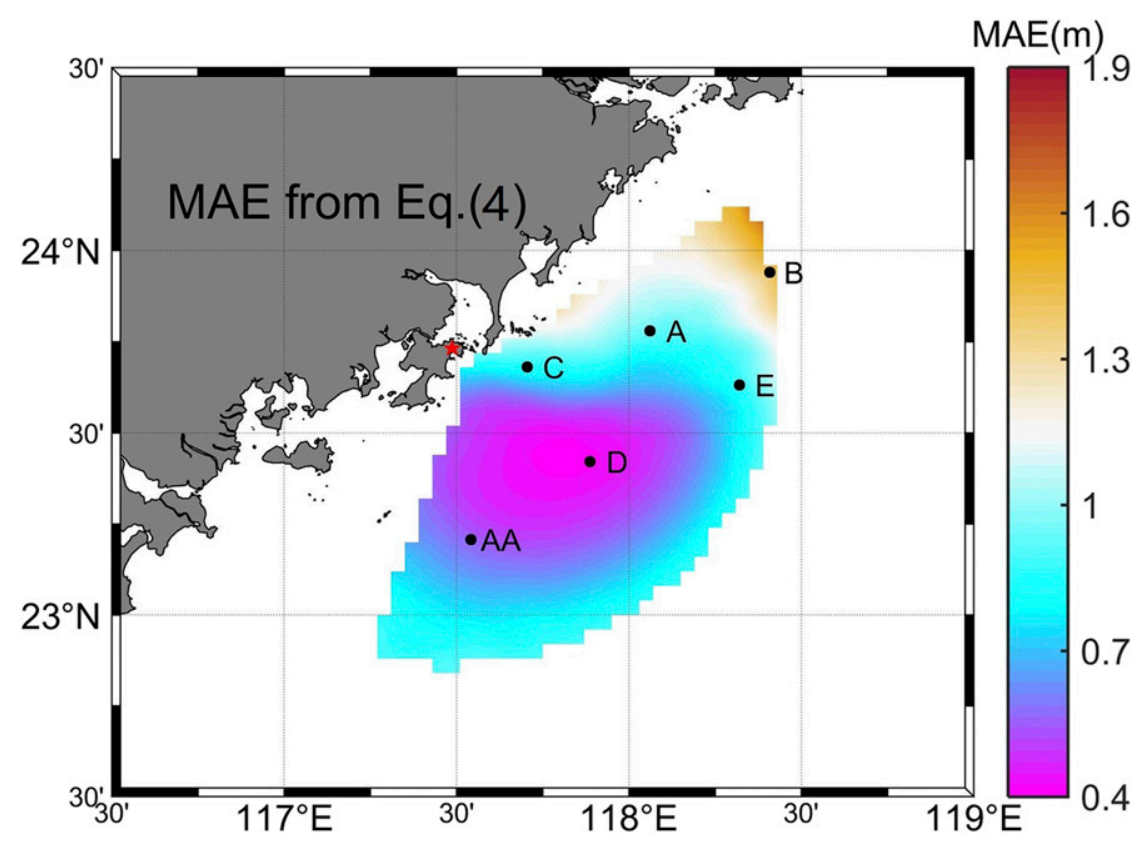

FIG. 9. Spatial distribution of MAE for radar-derived Hs obtained using Eq. (4). 
Fig. 4, suggesting that the fitting result was reasonable. The spatial distribution function of the MAE might provide a new method for systematic error correction of radar-derived Hs.

\section{Summary}

We presented a performance evaluation for the period 5-27 January 2014 to assess the utility of a single OS081H-A HF radar for mapping $\mathrm{Hs}$ in the southwestern Taiwan Strait. We considered a region with percent coverage of $>90 \%$ (i.e., the range was less than $100 \mathrm{~km}$ ) as our study area. Qualitative and quantitative comparisons were made based on in situ Hs data retrieved from five moored buoys and simulation results produced by the SWAN model.

Comparison of radar and buoy Hs showed that the MAE of radar-derived Hs was within the range 0.48$0.80 \mathrm{~m}$ and that the RMSE was within the range $0.57-$ $0.89 \mathrm{~m}$ (except at station B). However, for in situ Hs of $<1.5 \mathrm{~m}$, because the second-order sea echoes were weak and of poor stability, the accuracy of radarderived Hs was poor.

Comparison of the SWAN model and in situ Hs showed that the model-predicted $\mathrm{Hs}$ had MB from -0.45 to $-0.16 \mathrm{~m}$, MAE of $0.24-0.45 \mathrm{~m}$, and RMSE of $0.31-0.54 \mathrm{~m}$ in the study area. The model-predicted Hs was a slight underestimation, which could lead to augmentation of the errors between the model-predicted $\mathrm{Hs}$ and radar-derived $\mathrm{Hs}$ in most of the study area. However, the simulated Hs could be considered acceptable for use as sea truth to evaluate the HF radarderived Hs. Therefore, we evaluated the radar-derived Hs within the study area based on validated modelpredicted Hs. Four principal findings were elucidated from the evaluation results. 1) The MAE of radarderived $\mathrm{Hs}$ was significantly larger at the upper edge of the sector than in other areas (MAE $\leq 1 \mathrm{~m}$ for $83 \%$ of the area within the sector), and the MAE in the high-precision area was $<0.6 \mathrm{~m} \mathrm{(34 \%} \mathrm{of} \mathrm{the} \mathrm{area} \mathrm{within}$ the sector). 2) For model-predicted $\mathrm{Hs}$ of $\geq 1.5 \mathrm{~m}$, the MAE of radar-derived $\mathrm{Hs}$ was $\leq 1 \mathrm{~m}$ for $86 \%$ of the sector (except at the edge of sector). Particularly, MAE was $<0.6 \mathrm{~m}$ for $63 \%$ of the sector, which was mainly distributed in the area with a bearing from $-50^{\circ}$ to $+70^{\circ}$ and a range of $20-70 \mathrm{~km}$. The results are promising, but more work is needed. 3) A spatial distribution function was employed for the MAE of the HF radar-derived Hs based on the range, bearing, and mean radar-derived Hs over the sample duration, which could provide a new method for systematic error correction of radar-derived Hs. However, theoretical analysis showed that part of the error was due to the dependence of radar-derived $\mathrm{Hs}$ on the dominant wave direction. The spatial distribution function could change in different wave conditions. 4) The CC was useful in assessing the performance of radar-derived $\mathrm{Hs}$, which probably indicated the effect of shallow waters and the sand waves on the TB.

When ocean waves are high, the radar spectrum can become saturated. When such saturation occurs, there is no clear division between first- and second-order spectra, which could affect the accuracy of radar-derived Hs (Lipa and Nyden 2005). In this study, the in situ Hs data collected over the sample duration were $<5 \mathrm{~m}$, and the observation time was concentrated in winter when the wind direction was predominantly from the northeast. Hence, further research should consider additional data from different seasons, under different sea states, and with different environmental conditions.

Acknowledgments. This work was funded by the National Key Research and Development Program of China (2017YFC1404801). We thank the CSIC Pride (Nanjing) Intelligent Equipment System Co., Ltd., for providing radar and in situ data. We also thank NASA PO.DAAC for the generation and distribution of CCMP wind data. We also thank James Buxton, M.Sc., from Liwen Bianji, Edanz Group China (www.liwenbianji.cn./ac) for editing the English text of this paper.

\section{REFERENCES}

Atan, R., J. Goggins, M. Harnett, P. Agostinho, and S. Nash, 2016: Assessment of wave characteristics and resource variability at a 1/ 4-scale wave energy test site in Galway Bay using waverider and high frequency radar (CODAR) data. Ocean Eng., 117, 272-291, https://doi.org/10.1016/j.oceaneng.2016.03.051.

Bailard, J. A., J. W. Devries, and J. T. Kirby, 1992: Considerations in using Bragg reflection for storm erosion protection. J. Waterw. Port Coastal Ocean Eng., 118, 62-74, https://doi.org/10.1061/(ASCE)0733-950X(1992)118:1(62).

Barrick, D. E., 1971: Theory of HF and VHF propagation across the rough sea. 2: Application to HF and VHF propagation above the sea. Radio Sci., 6, 527-533, https://doi.org/10.1029/ RS006i005p00527.

_ 1972: Remote sensing of sea-state by radar. Remote Sensing of the Troposphere, V. E. Derr, Ed., U.S. Government Printing Office, 12-1-12-46.

_ 1977a: Extraction of wave parameters from measured HF radar sea-echo Doppler spectra. Radio Sci., 12, 415-424, https://doi.org/10.1029/RS012i003p00415.

_ 1977b: The ocean waveheight nondirectional spectrum from inversion of the HF sea-echo Doppler spectrum. Remote Sens. Environ., 6, 201-227, https://doi.org/10.1016/ 0034-4257(77)90004-9.

_ J. M. Headrick, R. W. Bogle, and D. D. Crombie, 1974: Sea backscatter at HF: Interpretation and utilization of the echo. Proc. IEEE, 62, 673-680, https://doi.org/10.1109/PROC.1974.9507.

—, M. W. Evans, and B. L. Weber, 1977: Ocean surface currents mapped by radar. Science, 198, 138-144, https://doi.org/ 10.1126/science.198.4313.138. 
Booij, N., R. C. Ris, and L. H. Holthuijsen, 1999: A thirdgeneration wave model for coastal regions: 1 . Model description and validation. J. Geophys. Res., 104, 7649-7666, https://doi.org/10.1029/98JC02622.

Capon, J., 1969: High-resolution frequency-wavenumber spectrum analysis. Proc. IEEE, 57, 1408-1418, https://doi.org/10.1109/ PROC.1969.7278.

Chu, X. L., J. Zhang, S. Y. Wang, Y. G. Ji, and Y. M. Wang, 2015: Improved empirical model for significant wave height inversion from high-frequency surface wave radar (in Chinese). J. Syst. Eng. Electron., 37, 1793-1796, https://doi.org/10.3969/ j.issn.1001-506X.2015.08.12.

Crombie, D. D., 1955: Doppler spectrum of sea echo at $13.56 \mathrm{Mc} . / \mathrm{s}$. Nature, 175, 681-682, https://doi.org/10.1038/175681a0.

Feng, M., W. J. Zhang, L. I. Yan, J. Shi, and Y. C. Zhang, 2013: The study of fine-scale precision wave forecasting system in the Taiwan Strait (in Chinese). Mar. Forecasts, 30, 42-48, https:// doi.org/10.11737/j.issn.1003-0239.2013.02.007.

Graber, H. C., B. K. Haus, R. D. Chapman, and L. K. Shay, 1997: $\mathrm{HF}$ radar comparisons with moored estimates of current speed and direction: Expected differences and implications. J. Geophys. Res., 102, 18 749-18 766, https://doi.org/10.1029/ 97JC01190.

Guo, T. T., W. Y. Gao, Y. Gao, and F. Gong, 2010: An analysis of the climate characteristics for Taiwan Strait (in Chinese). Mar. Forecasts, 27, 53-58, https://doi.org/10.11737/j.issn.10030239.2010.01.010.

Haus, B. K., L. K. Shay, P. A. Work, G. Voulgaris, R. J. Ramos, and J. Martinezpedraja, 2010: Wind speed dependence of single-site wave-height retrievals from high-frequency radars. J. Atmos. Oceanic Technol., 27, 1381-1394, https:// doi.org/10.1175/2010JTECHO730.1.

Heron, S. F., and M. L. Heron, 1998: A comparison of algorithms for extracting significant wave height from HF radar ocean backscatter spectra. J. Atmos. Oceanic Technol., 15, 1157-1163, https://doi.org/10.1175/1520-0426(1998)015<1157:ACOAFE> 2.0.CO;2.

Hisaki, Y., 2014: Inter-comparison of wave data obtained from single high-frequency radar, in situ observation, and model prediction. Int. J. Remote Sens., 35, 3459-3481, https://doi.org/ 10.1080/01431161.2014.904971.

Ji, H. D., Y. Y. Lan, and D. B. Zhao, 2013: Application of SWAN in Taiwan Strait typhoon waves numerical simulation (in Chinese). J. Waterw. Harbor, 34, 113-117, https:// doi.org/10.3969/j.issn.1005-8443.2013.02.007.

Kohut, J. T., H. J. Roarty, and S. M. Glenn, 2006: Characterizing observed environmental variability with HF Doppler radar surface current mappers and acoustic Doppler current profilers: Environmental variability in the coastal ocean. IEEE J. Oceanic Eng., 31, 876-884, https://doi.org/10.1109/ JOE.2006.886095.

Kuang, F. F., Y. Q. Zhang, J. P. Zhang, and C. Jia, 2015: Comparison and evaluation of three sea surface wind products in Taiwan Strait (in Chinese). Acta Oceanol. Sin., 37, 44-53, https://doi.org/10.3969/j.issn.0253-4193.2015.05.005.

Kundu, P. K., 1976: Ekman veering observed near the ocean bottom. J. Phys. Oceanogr., 6, 238-242, https://doi.org/10.1175/ 1520-0485(1976)006<0238:EVONTO > 2.0.CO;2.

Lin, Y. L., and K. M. Liao, 1983: The wave study in the Taiwan Strait (in Chinese). J. Appl. Oceanogr., 2, 20-28.

Lipa, B., and B. Nyden, 2005: Directional wave information from the SeaSonde. IEEE J. Oceanic Eng., 30, 221-231, https:// doi.org/10.1109/JOE.2004.839929.
—, D. Barrick, A. Alonso-Martirena, M. Fernandes, M. I. Ferrer, and B. Nyden, 2014: Brahan project high frequency radar ocean measurements: Currents, winds, waves and their interactions. Remote Sens., 6, 12 094-12 117, https://doi.org/ 10.3390/rs61212094.

Liu, Y. G., R. H. Weisberg, and C. R. Merz, 2014: Assessment of CODAR SeaSonde and WERA HF radars in mapping surface currents on the west Florida shelf. J. Atmos. Oceanic Technol., 31, 1363-1382, https://doi.org/10.1175/ JTECH-D-13-00107.1.

Long, R. M., D. Barrick, J. L. Largier, and N. Garfield, 2011: Wave observations from central California: SeaSonde Systems and in situ wave measurements. J. Sens., 2011, 728936, https://doi.org/10.1155/2011/728936.

Lorente, P., and Coauthors, 2018: Extreme wave height events in NW Spain: A combined multi-sensor and model approach. Remote Sens., 10, 1, https://doi.org/10.3390/rs10010001.

Ris, R. C., L. H. Holthuijsen, and N. Booij, 1999: A thirdgeneration wave model for coastal regions: 2 . Verification. J. Geophys. Res., 104, 7667-7681, https://doi.org/10.1029/ 1998JC900123.

Rogers, W. E., P. A. Hwang, and D. W. Wang, 2003: Investigation of wave growth and decay in the SWAN model: Three regional-scale applications. J. Phys. Oceanogr., 33, 366-389, https://doi.org/10.1175/1520-0485(2003)033<0366:IOWGAD> 2.0.CO;2.

Shao, H., Y. Li, and L. Li, 2011: Sun glitter imaging of submarine sand waves on the Taiwan Banks: Determination of the relaxation rate of short waves. J. Geophys. Res., 116, C06024, https://doi.org/10.1029/2010JC006798.

Wu, X. B., S. C. Wu, B. Y. Wen, S. L. Yang, and H. Chen, 2001: Application of minimum variation method in extracting space spectrum from wide-beam HF ground wave radar detection. J. Wuhan Univ., 47, 626-629, https://doi.org/10.14188/j.16718836.2001.05.025.

—, L. Li, Y. X. Shao, Y. Li, and T. Guo, 2009: Experimental determination of significant waveheight by OSMAR071: Comparison with results from buoy. Wuhan Univ. J. Nat. Sci., 14, 499-504, https://doi.org/10.1007/s11859-009-0608-8.

Wyatt, L. R., 2002: An evaluation of wave parameters measured using a single HF radar system. Can. J. Remote Sens., 28 , 205-218, https://doi.org/10.5589/m02-018.

_ S. P. Thompson, and R. R. Burton, 1999: Evaluation of high frequency radar wave measurement. Coastal Eng., 37, 259282, https://doi.org/10.1016/S0378-3839(99)00029-0.

— , and Coauthors, 2003: Validation and intercomparison of wave measurements and models during the EuroROSE experiments. Coastal Eng., 48, 1-28, https://doi.org/10.1016/ S0378-3839(02)00157-6.

_ J. J. Green, A. Middleditch, M. D. Moorhead, J. Howarth, M. Holt, and S. Keogh, 2006: Operational wave, current, and wind measurements with the Pisces HF radar. IEEE J. Oceanic Eng., 31, 819-834, https://doi.org/10.1109/ JOE.2006.888378.

Zhang, H. G., X. L. Lou, A. Q. Shi, X. K. He, W. B. Guan, and D. L. Li, 2014: Observation of sand waves in the Taiwan Banks using HJ-1A/1B sun glitter imagery. J. Appl. Remote Sens., 8, 083570, https://doi.org/10.1117/1.JRS.8.083570.

Zhang, Y., Y. Li, H. Shao, Y. Zhong, S. Zhang, and Z. Zhao, 2012: Band gaps and localization of surface water waves over largescale sand waves with random fluctuations. Phys. Rev., 85E, 066319, https://doi.org/10.1103/PhysRevE.85.066319. 